\title{
CONTROL OF INDUCTION MOTOR BASED ON NEURAL ESTIMATOR
}

\author{
Peter GIROVSKÝ \\ Department of Electrical Engineering and Mechatronics, Faculty of Electrical Engineering and Informatics, \\ Technical University of Košice, Letná 9, 04200 Košice, Slovak Republic, Tel.: +421 55602 2271, E-mail: peter.girovsky@tuke.sk
}

\begin{abstract}
The paper deals with a sensorless control of induction motor based on neural network estimators. In the paper are presented simulation and results of designing neural estimators for observing the rotor magnetic current and the motor angular speed. The neural estimators of rotor magnetic current and angular speed for induction motor field oriented control were designed in MATLABSimulink. Controllers for simulation of shaft sensorless field oriented control have been designed by state space method.
\end{abstract}

Keywords: induction motor, neural network, sensorless control, vector control

\section{INTRODUCTION}

Motors play important roles in industrial producing and in many other applications. In their early days, d.c. motors had the advantage of precise speed control when utilized for the purpose of accurate driving. However, d.c. motors have the disadvantage of brush erosion, maintenance requirements, environmental effects, complex structures and power limits. On the other hand, induction motors are robust, small in size, low in cost, almost maintenance-free.

Hasse [9] and Blaschke [10] developed a field oriented control theory to simplify the structure of IM speed control used to drive the d.c. motor. In recent years, the field oriented control theory has become more feasible due to progress in the development of electronics techniques and high-speed microprocessors. Nonlinear control problems can often be solved if full state information is available; in the IM case the rotor states are immeasurable and often the angular speed of the rotor is too costly to be monitored.

In most applications, speed sensors are necessary in the speed control loop. On the other hand, there are applications where lower performance is required, cost reduction and high reliability are necessary, or hostile environment does not allow using speed sensors. In these fields, speed sensorless IM control can be usefully applied. Many different solutions for the estimation of states variables or model parameters have been proposed currently, for example estimators utilizing the motor construction properties, estimators based on the drive dynamic model or estimators based on artificial intelligence $[7,8,13,15,16]$.

Sensorless controllers, depending on adaptive control and observer theory, on optimal observer design by applying Kalman filter theory $[11,12]$, on sliding mode control $[2,3]$, and using artificial intelligence methods $[1$, $4,5,6,14]$ have been proposed.

At present, requirements on the dynamic precision are not too strict and virtual or soft sensors are alternatively successfully utilized. Estimators based on artificial intelligence are divided into the following groups:

- systems based on the fuzzy logic,

- $\quad$ systems based on neural networks,

- $\quad$ systems based on hybrid systems,
- systems based on evolutionary algorithms (genetic algorithms).

\section{DESIGN OF NEURAL ESTIMATOR FOR CONTROL OF INDUCTION MOTOR}

The neural modelling can perform estimation of the induction motor angular speed or of other non-measurable variables on the neural networks base.

Nowadays, commonly used in the industry there are field oriented controlled drives based on different solutions and performances. With field-oriented techniques, the decoupling of flux and torque control commands of the IM is guaranteed, and the induction motor can be controlled linearly like a separately excited DC motor. The DC motor like performance can be obtained by preserving a fixed and orthogonal orientation between the field and armature fields in the induction motor by orientation of the stator current with respect to the rotor flux in order to attain independently controlled flux and torque. Block diagram of the control scheme is presented in figure 1.

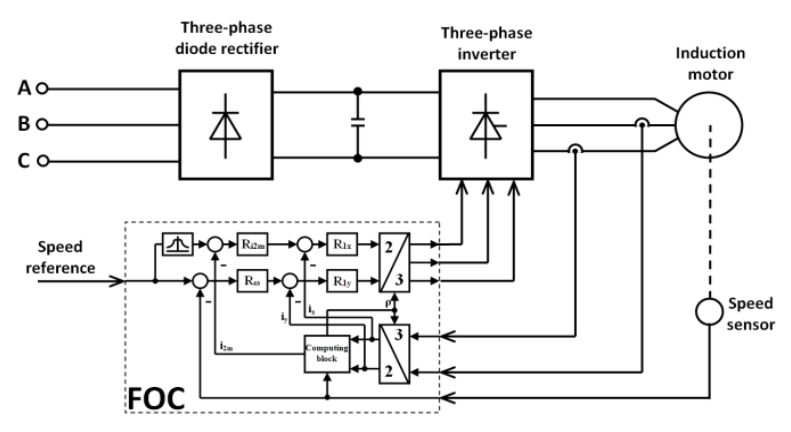

Fig. 1 Basic field oriented control scheme

Using the field oriented control principle, the stator current component $i_{d l}$ is aligned in the direction of the rotor flux vector and the stator current component $i_{q 1}$ is aligned in the direction perpendicular to it. The rotor flux orientation in the squirrel-cage rotor IM cannot be directly measured, but it can be obtained from terminal variables.

After using transformation of coordinates $d, q$ to the rotating system $x-y$, the electric torque is proportional to the $i_{l y}$ component and the relation between the rotor flux 
and $i_{l x}$ component is given by the first order linear transfer function with $T_{2}=L_{2} / R_{2}$ time constant.

From this fact and for the considered flux control, the stator current and voltage components were chosen as input signals for reconstruction of the induction motor speed. The developed estimators were trained according to selected training patterns from the direct field oriented control of the induction motor.

\subsection{Induction motor FOC simulation design}

In the design of state control by method of the poles determine for two input variables and one output based on the following equations:

$$
\begin{aligned}
& \sigma T_{1} \frac{d i_{1 x}}{d t}+i_{1 x}=\frac{K_{T} u_{1 x}}{R_{1}}-(1-\sigma) T_{1} \frac{d i_{2 m}}{d t}+\sigma T_{1} \omega_{2 m} i_{1 y} \\
& \sigma T_{1} \frac{d i_{1 y}}{d t}+i_{1 y}=\frac{K_{T} u_{1 y}}{R_{1}}-(1-\sigma) T_{1} \omega_{2 m} i_{2 m}-\sigma T_{1} \omega_{2 m} i_{1 x} \\
& T_{2} \frac{d i_{2 m}}{d t}+i_{2 m}=i_{1 x} \\
& \frac{i_{1 y}}{T_{2} i_{2 m}}+\omega=\omega_{2 m} \\
& \frac{J}{p} \frac{d \omega}{d t}=\frac{3 p}{2} \frac{L_{h}}{1+\sigma_{2}} i_{2 m} i_{1 y}-m_{z}
\end{aligned}
$$

Define the state variables: $i_{2 m}=x_{1} ; i_{1 x}=x_{2} ; \omega=x_{3} ; i_{1 y}=x_{4}$; $m_{z}=z ; u_{1}=u_{1 x} / K_{T} ; u_{2}=u_{1 y} / K_{T}$.

Then, written can be the state equation for induction motor:

$$
\dot{x}=\left[\begin{array}{c}
-a_{1} x_{1}+a_{1} x_{2} \\
f_{2}(\underline{x}) \\
a_{3} x_{1} x_{4} \\
f_{4}(\underline{x})
\end{array}\right]+\left[\begin{array}{cc}
0 & 0 \\
b & 0 \\
0 & 0 \\
0 & b
\end{array}\right] \cdot \underline{u}+\left[\begin{array}{c}
0 \\
0 \\
-e \\
0
\end{array}\right] . z=a(x)+B . u+e . z
$$

$$
y=x_{3}=c(x)
$$
(6):

The constants and functions used in the state equation

$$
\begin{gathered}
a_{1}=\frac{1}{T_{2}} ; a_{2}=\frac{1}{\sigma T_{1}} ; a_{3}=\frac{3 p^{2}}{2 J} \frac{L_{h}}{1+\sigma_{2}} ; a_{4}=\frac{1-\sigma}{\sigma} ; \\
\sigma_{2}=\frac{L_{2 \sigma}}{L_{h}} ; \sigma=1-\frac{L_{h}^{2}}{L_{1} \cdot L_{2}} ; b=\frac{K_{T}}{\sigma L_{1}} ; e=\frac{p}{J} \\
f_{2}(\underline{x})=a_{1} \cdot a_{4} \cdot x_{1}-\left(a_{2}+a_{1} \cdot a_{4}\right) \cdot x_{2}+x_{3} \cdot x_{4}+a_{1} \cdot \frac{x_{4}^{2}}{x_{1}} \\
f_{4}(\underline{x})=-\left(a_{2}+a_{1} \cdot a_{3}\right) \cdot x_{4}-a_{4} \cdot x_{1} \cdot x_{3}-x_{2} \cdot x_{3}-a_{1} \cdot \frac{x_{2} \cdot x_{4}}{x_{1}}
\end{gathered}
$$

Nonlinear function $f_{2}(x), f_{4}(x)$ in the control scheme shown in Fig. 2 compensating for introduction of control $u$, so as to simplify the state equation:

$$
\begin{aligned}
& u=\frac{1}{b}\left[\begin{array}{l}
-f_{2}(x)+v_{2}-r \cdot x_{2} \\
-f_{4}(x)+v_{4}-r \cdot x_{4}
\end{array}\right] \\
& \dot{x}=\left[\begin{array}{cccc}
-a_{1} & a_{1} & 0 & 0 \\
0 & -r_{2} & 0 & 0 \\
0 & 0 & 0 & a_{3} \\
0 & 0 & 0 & -r_{4}
\end{array}\right] \underline{x}+\left[\begin{array}{ll}
0 & 0 \\
1 & 0 \\
0 & 0 \\
0 & 1
\end{array}\right] \cdot\left[\begin{array}{l}
v_{2} \\
v_{4}
\end{array}\right]
\end{aligned}
$$

From the characteristic polynomial of all controller circuits were calculated constants for field oriented control scheme.

\subsection{Magnetising current neural estimator}

If for vector control the $x$-th component of the stator current vector is considered as a basis of current-creating component then the magnetising current $i_{2 m}$ estimator will process current-creating component of the stator current.

As mentioned above, the magnetising current $i_{2 m}$ neural estimator bases its estimation of the currentcreating component of stator current $i_{1 x}$. Dependence between currents $i_{2 m}$ and $i_{1 x}$ is linear, and hence the estimator can be made up of a feed-forward neural network without any hidden layer. For the activating function the purelin linear function can be used. The input data vector consists of values of the stator current $i_{l x}$ in step $(k)$ and step $(k-1)$, respectively, and also the preceding value of magnetising current $i_{2 m}$ in step $(k-1)$. Basic equation of such neural estimator we can describe as:

$$
\underline{O}=f\left[\sum \underline{I}_{w_{i}}+\underline{b i a s}\right]
$$

Here, $\underline{\boldsymbol{O}}$ stands for output values vector here, $\underline{\boldsymbol{I}}$ is the input data vector and $\boldsymbol{w}_{\boldsymbol{i}}$ presents weights of individual connections of neurons. Substituting the input matrix to equation (7), we will obtain the equation for the magnetising current neural estimator in the following form:

$i_{2 m}(k)=$ purelin $\left(\left[\begin{array}{c}i_{1 x}(k) \\ i_{1 x}(k-1) \\ i_{2 m}(k-1)\end{array}\right] \underline{w}_{i}+\right.$ bias $)$

where current $i_{2 m}(k)$ is the output variable and the input variables are $i_{1 x}(k), i_{1 x}(k-1)$ and $i_{2 m}(k-1)$.

\subsection{Magnetising current neural estimator}

If for the basis of torque-creating component we establish the $y$-th component of the vector then the speed estimator will estimate this torque creating component from the stator voltage and current.

As it was already mentioned above, the angular speed $\omega$ neural estimator bases its estimation on the torque component of stator voltage $u_{l y}$ and current $i_{l y}$. The relation between the input and output quantities is not represented by a simple linear dependency, and this is the reason why for the estimation a cascade neural network with one hidden layer consisted of eight neurons will be 
used. As an activating function for the hidden layer used there was the tansig nonlinear function and for the output layer used was a purelin linear function. The input data vector is represented by values of stator voltage $u_{l y}$ and stator current $i_{l y}$ in steps $(k)$ and $(k-1)$, as well as by value of magnetising current $i_{2 m}$ in steps $(k)$ and $(k-1)$. Simply we can describe this neural estimator as:

$$
\begin{aligned}
& \underline{A}=f_{1}\left[\sum \underline{I} \cdot \underline{w}_{i}+\text { bias }_{1}\right] \\
& \underline{O}=f_{2}\left[\sum\left(\underline{A}^{\cdot} \underline{w}_{j}+\underline{I}^{\prime} \underline{w}_{k}\right)+\text { bias }_{2}\right]
\end{aligned}
$$

Here, $\underline{\boldsymbol{O}}$ is the output values vector, $\underline{\boldsymbol{I}}$ present a vector of input variables and $w_{i}, w_{j}, w_{k}$ are weights of individual connections of neurons. Post substituting the input matrix to equation (9) the neural speed estimator can be described by the following equation:

$\omega(k)=$ purelin $\left(\left[\begin{array}{c}u_{1 y}(k) \\ u_{1 y}(k-1) \\ i_{1 y}(k) \\ i_{1 y}(k-1) \\ i_{2 m}(k) \\ i_{2 m}(k-1)\end{array}\right] \underline{w}_{j}+\right.$ tansig $\left(\left[\begin{array}{c}u_{1 y}(k) \\ u_{1 y}(k-1) \\ i_{1 y}(k) \\ i_{1 y}(k-1) \\ i_{2 m}(k) \\ i_{2 m}(k-1)\end{array}\right] \underline{w}_{i}+\right.$ bias 1$) \underline{w}_{k}+$ bias 2$)$

where the output quantity is $\omega(k)$ angular speed value and where the input are values $u_{l y}(k), u_{1 y}(k-1), i_{l y}(k), i_{l y}(k-1)$, $i_{2 m}(k)$ and $i_{2 m}(k-1)$.

\section{RESULTS}

In the following, shown there are simulation results of sensorless vector control of an induction motor when applying neural estimators of the speed and magnetising current, respectively.

The principal diagram of the vector control with connected neural estimators of the magnetising current and speed is shown in figure 2 .

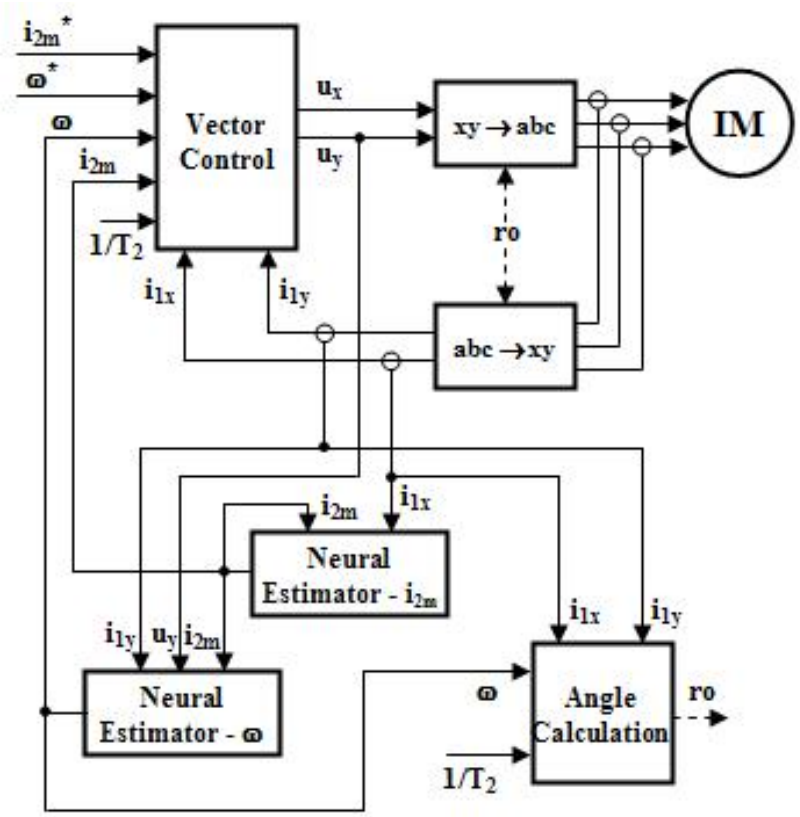

Fig. 2 Basic diagram of vector control with neural estimators
Simulation, design and training of neural estimators were performed for the induction motor with parameters: $P_{n}=0,75 \mathrm{~kW} ; U_{n}=220 \mathrm{~V} / 380 \mathrm{~V} ; I_{n}=3,8 \mathrm{~A} / 2,2 \mathrm{~A} ; n_{n}=1380$ $\mathrm{rpm} ; p=2 ; s=0,08 ; J=5,4.10^{-3} \mathrm{kgm}^{2}$.

Figure 3 and figure 4 shows a comparison of real and observed values of the magnetizing current and the angular speed, whilst shown by a dashed line there is the required angular speed value during starting, reversing and loading transients. In time of $2 \mathrm{~s}$ the motor was loaded by the rated load torque.

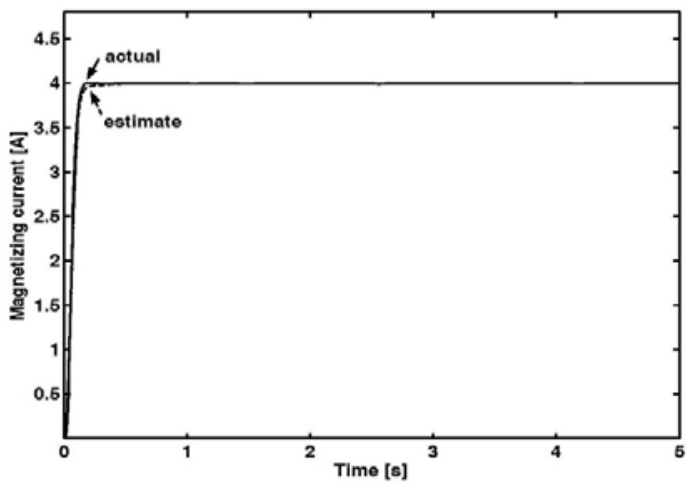

Fig. 3 Comparison of the estimated versus actual magnetising current

The waveforms shown in figure 3 and figure 4 are valid for case of no feedback to control from the neural observers but led directly from the motor mathematical model.

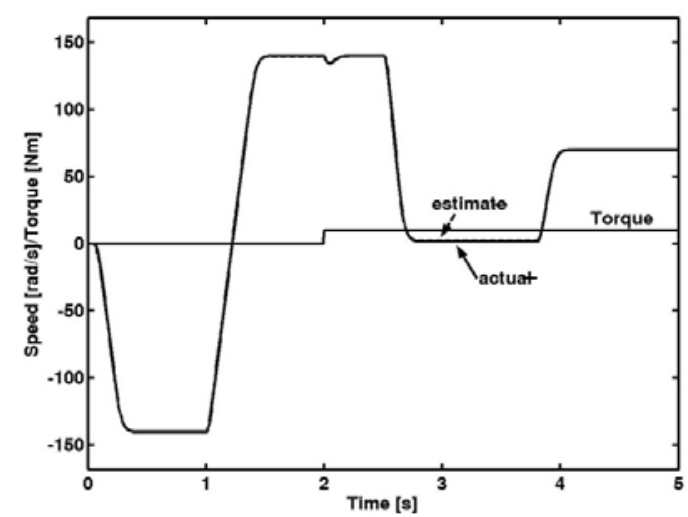

Fig. 4 Comparison of the estimated versus actual speed of the IM

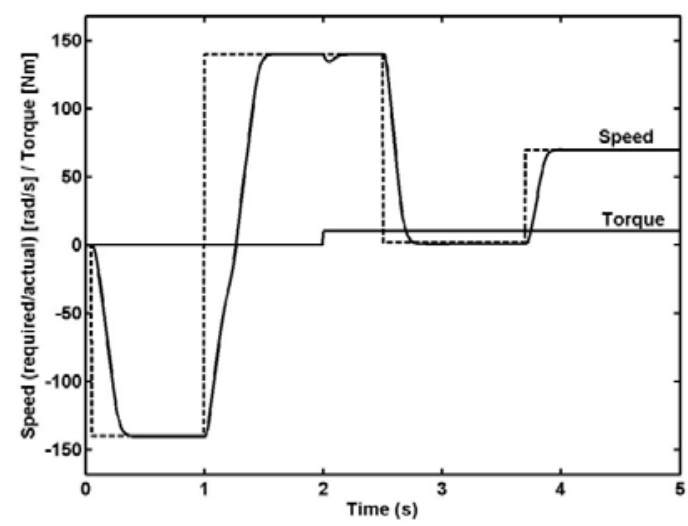

Fig. 5 Transients of desired versus real angular speed and the motor load torque 
Shown in figure 5 is a simulated response of the induction motor angular speed (in solid line) at conditions identical with the previous one, shown in figure 5. In this case, and the same as in any following ones, the feedback to control was introduced from neural observers of the magnetising current and angular speed.

\section{CONCLUSIONS}

The paper presents design of induction motor neural estimator of rotor magnetising current and rotor speed. Based on easily measurable quantities such as components of stator current and voltage the estimators of magnetising current and rotor speed were designed utilising feedforward and cascade neural networks. Both these networks were trained off-line using the LevenbergMarquardt algorithm, which is a modification of the traditional back-propagation training algorithm.

The simulation results presented via corresponding time functions illustrate and validate the possibility of artificial neural networks exploitation for sensorless control of induction motor while showing also their main advantages as adaptability and robustness.

\section{REFERENCES}

[1] VAS, P.: Artificial-intelligence-based electrical machines and drives, Oxford University Press, Oxford, 1999.

[2] VITTEK, J. - DODDS, S. J. - MAKY ̌̆, P. LEHOCKÝ, P.: An Observer Design for Forced Dynamics Control of AC Drives, Transcom 2007, Žilina, Slovakia, 2007, pp. 207-210.

[3] VITTEK, J. - BRIS, P. - ŠTULRAJTER, M. PÁCHA, M.: Chattering free sliding mode control law for position control of the drive employing induction motor, Power Engineering Conference 2008, AUPEC '08, Australasian Universities, 14-17 Dec., 2008, pp. 1-6.

[4] KUCHAR, M. - BRANDŠTETTER, P. KADUCH, M.: Sensorless induction motor drive with neural network, IEEE, Annu. Power Elec. Specialists Conf. m., 2004, pp. 3301-3305.

[5] JOVANKOVIČ, J. - ŽALMAN, M.: Application of the virtual sensors based on the artificial neural networks, EDPE'03, International conference, Slovakia, 2003, pp. 486-490.

[6] BENSALEM, Y. - ABBOUD, W. - SBITA, L. ABDELKRIM, M. N.: A Sensorless Neural Network Speed Control of Induction Motor Drive, Int. Journal of Signal System Control and Engineering Application 1 (2), 2008, pp. 150-158.
[7] JADLOVSKÁ, A. - KABAKOV, N. SARNOVSKÝ, J.: Predictive Control Design Based on Neural Model of a Non-linear System, Acta Polytechnica Hungarica, Vol. 5, No. 4, 2008, pp. 93108.

[8] JAMUNA, V. - REDDY, S. R.: Modeling and speed control of induction motor drives using neural network, Annals of Diarea de Jos University of Galati, III., Vol. 33, No. 1, 2010, pp. 40-49.

[9] HASSE, K.: Zur Dynamik Drehzahlgeregelter Antriebe mit stromrichtergespeisten Asynchronkurschlusslaüfer Maschinen, Techn. Hochsch: Darmstadt, Dissertation, 1969, pp. 74-78.

[10] BLASCHKE, F.: The Principle of Field Orientation as Applied to the New Transvector Closed-Loop Control System for Rotating-Field Machines, Siemens Rev. 39 (5), 1972, pp. 217-220.

[11] MEZIANE, S. - TOUFOUTI, R. - BENALLA, H.: Nonlinear Control of Induction Machines Using an Extended Kalman Filter, Acta Polytechnica Hungarica, Vol. 5, No. 4, 2008, pp. 41-58.

[12] ŽILKOVÁ, J. - TIMKO, J. - BERKO, J.: Speed Sensorless Control of an Induction Motor Drive Using Extended Kalman Filter, Acta Technica ČSAV 50, No. 4, Prague, 2005, pp. 279-289.

[13] TIMKO, J. - ŽILKOVÁ, J. - BALARA, D.: Artificial neural networks application in electrical drives, (in Slovak), Calypso s.r.o., Košice, 2002, p. 239, ISBN 80-85723-27-1.

[14] TIMKO, J. - ŽILKOVÁ, J. - GIROVSKÝ, P.: Shaft Sensorless Vector Control of an Induction Motor, Acta Technica ČSAV, Vol. 52, No. 1, 2007, pp. 8191, ISSN 0001-7043.

[15] TIMKO, J. - ŽILKOVÁ, J. - GIROVSKÝ, P.: Modeling and control of electrical drives using neural networks, (in Slovak), C-Press, Košice, 2009, p. 202, ISBN 978-80-8086-124-7.

[16] ŽILKOVÁ, J. - TIMKO, J. - GIROVSKÝ, P.: Nonlinear System Control Using Neural Networks, Acta Polytechnica Hungarica, Vol. 3, No. 4, 2006, pp. 85-94.

Received May 27, 2016, accepted July 29, 2016

\section{BIOGRAPHY}

Peter Girovský was born on 1979. In 2009 he graduated at the department of Electrical Drives and Mechatronics of the Faculty of Electrical Engineering and Informatics at Technical University of Košice. His research interests include artificial intelligence, control systems, robotics. 